\title{
VIRUS-LIKE SYNDROMES OF CUCURBITA SPECIES HYBRIDS
}

\author{
THOMAS W. WHITAKER \\ Crops Research Division, A.R.S., U.S. Deportment of Agriculture, Lo Jollo, Colifornio \\ and \\ W. P. BEMIS \\ Deportment of Horticulture, University of Arizono, Tucson, Arizono
}

Received 12.xi.63

\section{INTRODUCTION}

DuRING the course of an investigation of species relationships in Cucurbita several striking morphological abnormalities appeared in progenies of species crosses. These abnormalities occurred at frequent intervals, in apparently random fashion. The present report describes and traces the origin of a group of these plants where the abnormalities can be separated into two essentially similar categories.

In external appearance the symptoms in abnormal plants resemble those in plants infected with a cucurbit virus. We have therefore termed the condition a "virus-like syndrome" of squash (see McNaughton and Harper, I960). There is good evidence to indicate, however, that the cause of the syndrome is not a virus. Dr R. E. Webb was unsuccessful in recovering the common cucurbit viruses from virus-like syndrome plants. Also, the symptoms do not spread from plant to plant in the field or the greenhouse, as one would expect if viruses were implicated. Insect vectors of virus were common in the fields and occasionally in the greenhouse at the time the plants were in culture. Thus it appears most probable that if the syndrome was caused by a virus, the virus would have had ample opportunity to spread by vectors to other plants. The syndrome apparently appears only in specific genetic combinations. This again suggests that the syndrome is of genetic origin rather than induced by a virus. Furthermore, the ability of virus-like syndrome plants to produce normal runners spontaneously argues against an infective agent such as a virus being the responsible agent.

A virus-like syndrome plant was first recorded in the summer of 1956. It appeared in plants of progenies from a series of interspecific hybrids and was invariably associated with the Cucurbita maxima Duch. genome. It is designated VLS (max). In 1962 a second viruslike syndrome, morphologically quite different and easily distinguished from VLS ( $\max$ ), was observed in derivatives of interspecific hybrids of Cucurbita. This second virus-like syndrome, which appears to be associated with the $C$. moschata Poir. genome, is designated VLS (mos). 


\section{MATERIALS AND METHODS}

VLS (max) originally appeared in crosses involving three species of Cucurbita. Cucurbita lundelliana Bailey was crossed with $C$. maxima cv. "Banana ". The $\mathrm{F}_{1}$ species hybrid was immediately crossed with two other species, $C$. pepo L. cv. "Zucchini" and $C$. moschata cv. "Long Genoa Queen". In progenies from these triple species hybrids, VLS ( $\max$ ) commonly occurred. It has continued to occur sporadically in derivatives from these crosses and in certain other triple species hybrids.

VLS (mos) appeared in $F_{1}$ progenies from 4 interspecific hybrids each of which had Cucurbita moschata cv. "Butternut" as a common parent. The $\mathrm{F}_{1}$ interspecific hybrids were $C$. moschata $\times C$. maxima; C. moschata $\times C$. palmata Wats.; C. moschata $\times$ C. digitata Gray; and $C$. lundelliana $\times C$. moschata. In addition to the combinations mentioned, a VLS (mos) plant appeared in a triple species hybrid involving C. mixta Pang., C. moschata, and C. lundelliana.

\section{OBSERVATIONS}

(i) Detailed description of plants with VLS (max)

A majority of the plants showing VLS ( $\max$ ) are smaller than normal, but vigorous and healthy. About a half are severely dwarfed. Some plants are normal except for the extreme tips of the runners on which leaf distortion and abnormally long tendrils may occur. Occasionally one entire runner of the plant may be completely normal, while the remainder of the plant shows the virus-like syndrome, or as McNaughton and Harper (1960) succinctly have stated, "the basal shoot has 'escaped' from the syndrome". In an extreme manifestation of the disorder the stems are sharply zig-zagged and have shortened internodes. The tendrils are long and stringy and occasionally branched (plate I, fig. I). Dwarf plants have greatly shortened or compressed internodes (plate I, fig. 2).

Leaves of plants with VLS (max) are frequently mottled and exhibit virus-like distortions. The lamina is asymmetrical and sharply pointed at the termination of the larger veins (plate I, fig. I). Also, it is unevenly thickened on the dorsal side. Thickening results from the piling-up of amorphous masses of palisade tissue. The uneven thickness of the lamina causes a peculiar rolling or cupping of the leaves (plate I, fig. 3). Many of the older leaves are dry and scaly but still green.

The pistillate flowers are occasionally normal, but the petals are usually malformed. On some plants the corolla of the pistillate flowers is absent and the calyx becomes petaliferous (plate II, fig. 2). Few fruits are set either by controlled or natural pollination. The staminate flowers are mostly absent; therefore these plants are functionally male-sterile. Dwarf plants usually lack reproductive organs of any kind.

(II) Detailed description of plants with VLS (mos)

Plants with VLS (mos) have primarily two symptoms: (I) dwarfing effect reducing the growth rate; and (2) the development of a mosaic pattern in all leaves of the plant (see plate II, fig. I) and to a 
lesser extent in the petals. The leaves and flowers in VLS (mos) plants are deformed, but the abnormalities are not nearly as severe as in plants with VLS (max). The staminate flowers develop and dehisce viable pollen. The pistillate flowers tend to abort before anthesis, but an occasional flower will mature. The stigma and ovary of such flowers are normal except for being dwarfed, but fruit set from these flowers is rare. Fruits that do develop are greatly reduced in size, and have a pebbled surface compared with the smooth surface of normal fruits (plate II, fig. 3 ).

The dwarfing effect of the VLS (mos) is shown by the data in table I. Dwarfing is expressed equally in all parts of the vine. These data represent the ultimate growth of normal and VLS (mos) runners

TABLE I

Lengths of internodes, petioles, leaf diameters, leaf lengths, and staminate-flower pedicels of normal and VLS (mos) runners

The data represent a 20-node, comparable length of runner of each type. The measurements are in inches.

\begin{tabular}{|l|c|c|c|c|c|}
\hline $\begin{array}{c}\text { Runner } \\
\text { type }\end{array}$ & $\begin{array}{c}\text { Internode } \\
\text { length }\end{array}$ & Petiole length & $\begin{array}{r}\text { Leaf } \\
\text { diameter }\end{array}$ & $\begin{array}{c}\text { Leaf length } \\
\text { at main vein }\end{array}$ & $\begin{array}{c}\text { Staminate } \\
\text { flower pedicel } \\
\text { length }\end{array}$ \\
\hline VLS (mos) & $3 \cdot 83 \pm 0.58$ & $5 \cdot 93 \pm 0 \cdot 40$ & $5 \cdot 75 \pm 0.46$ & $4 \cdot 29 \pm 0.25$ & $2 \cdot 05 \pm 0 \cdot 69$ \\
Normal & $5 \cdot 69 \pm 0.96$ & $13.43 \pm 0 \cdot 87$ & $9 \cdot 68 \pm 0.59$ & $6 \cdot 77 \pm 0.69$ & $6 \cdot 12 \pm 1 \cdot 39$ \\
\hline
\end{tabular}

from a plant that originally was completely VLS (mos), but had one runner spontaneously changed to normal.

In addition, the actual growth rate of the VLS (mos) runner is markedly reduced below that of a normal runner on the same plant. Growth measurements for leaf petiole length, blade width, and blade length at the fifth node from the first fully elongated internode of a VLS (mos) vine are $54.8,43.5$ and $52 \cdot 4$ per cent., respectively, of the fully developed organs; measurements at a comparable node of a normal runner are $78 \cdot 2,62^{\circ} \circ$ and 73.8 per cent. of the fully developed organs. These data which indicate the faster growth rate of normal runners are biased to the extent that normal internodes reach full elongation before the VLS (mos) internodes. In spite of bias in favour of the VLS (mos) runner the measurements suggest a much faster growth rate for the normal runner.

\section{(iii) Occurrence of plants with VLS (max)}

In attempting to establish a genetic basis for the VLS (max), we traced the pedigrees of progenies in which plants with this syndrome appeared. A study of the pedigrees from figures $I, 2,3$ and 4 suggests that the genome of Cucurbita maxima cv. "Banana" is apparently 


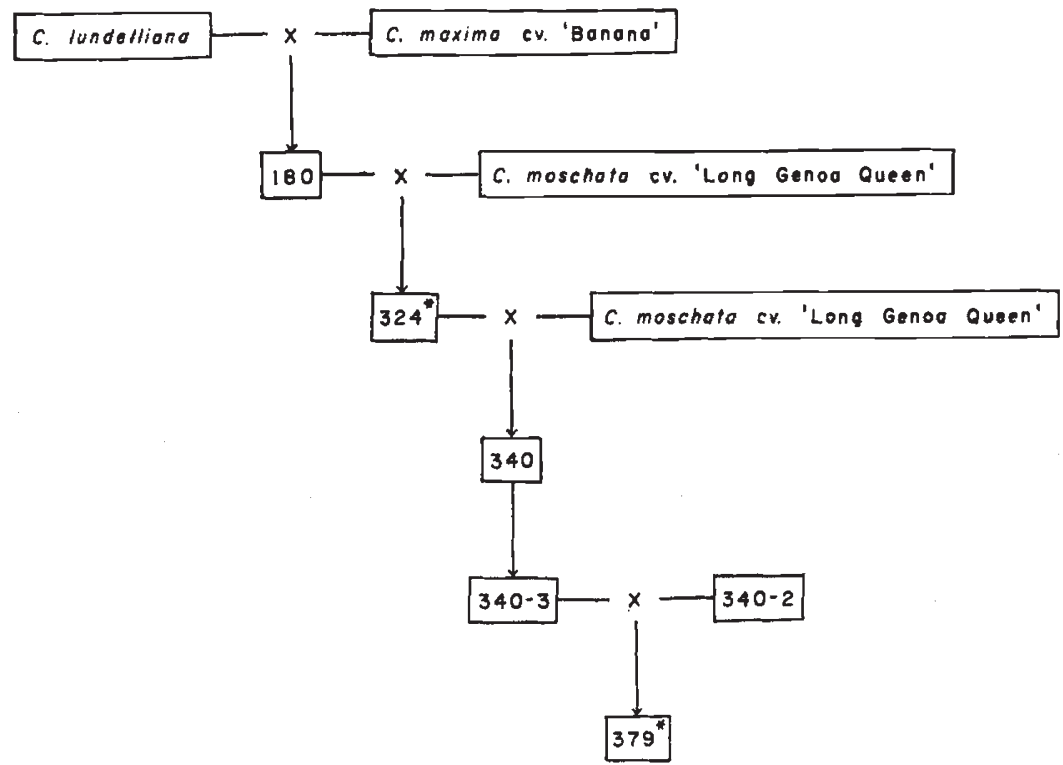

FIG. 1.-Pedigree of plants with VLS (max). Plants with this syndrome appeared in progenies 324 and 379 , marked with the asterisk.

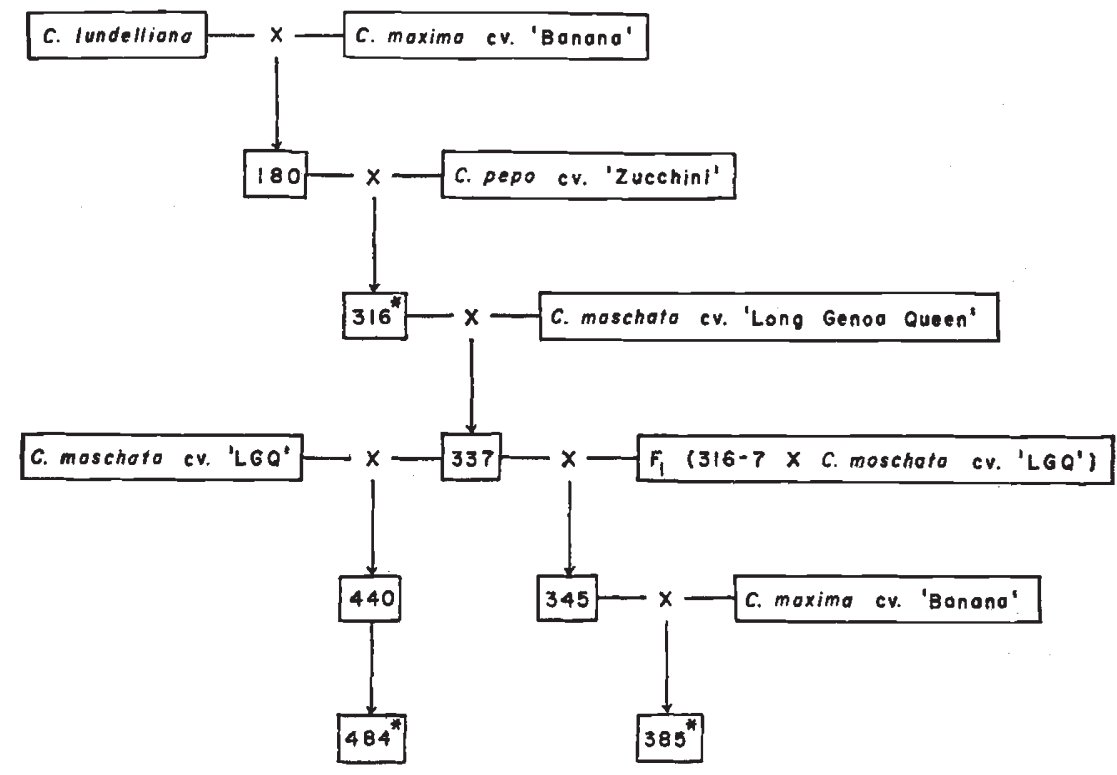

FIG. 2.-Pedigree of plants with VLS (max). Plants with this syndrome appeared in progenies $316,3^{85}$ and 484 , marked with the asterisk.

responsible for the incidence of such plants, since it is the only common element in the four pedigrees under consideration. The syndrome was not expressed in progenies from crosses of $C$. lundelliana $\times$ C. maxima, but as a third species, C. pepo or C. moschata, was introduced into the combination, the syndrome was immediately evident in more than 
$5^{\circ}$ per cent. of the plants (figs. I, 2 and 3 ). The virus-like syndrome has continued to appear in derivatives from these crosses, even though other species, $C$. mixta and $C$. sororia Bailey (see figs. 3 and 4 ) have been

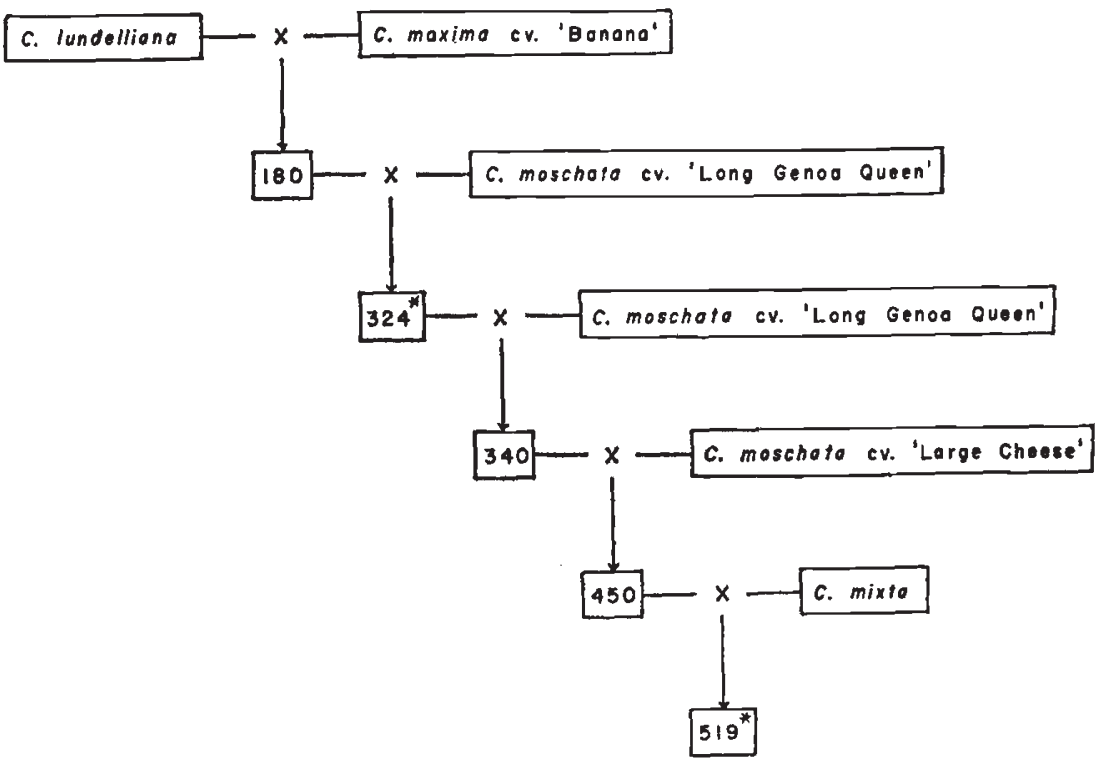

FIG. 3.-Pedigree of plants with VLS (max). Plants with this syndrome appeared in progenies 324 and 519 , marked with the asterisk.

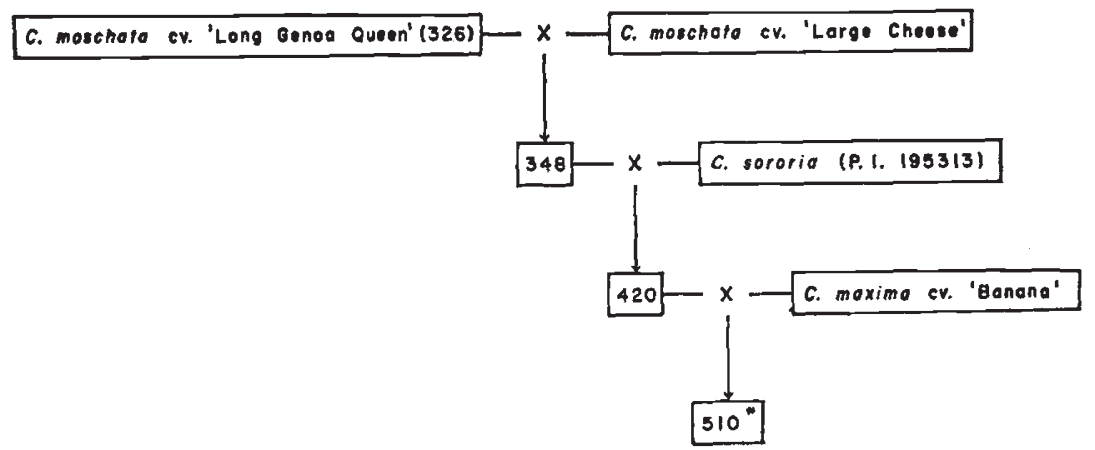

FIG. 4--Pedigree of plants with VLS (max). Plants with this syndrome appeared in progeny $5^{10}$, marked with the asterisk.

added. In fig. 4 it is apparent that as the C. maxima genome was introduced, plants with the virus-like syndrome appeared in the ensuing progeny. Further plants with VLS $(\max )$ do not occur until combinations with genomes from three species have been synthesised, and moreover, one species in the triple combination must be C. maxima for the syndrome to find expression.

There is one exception to the rule that the genomes of three species are required to produce VLS $(\max )$. The junior author found in his 
cultures a plant that was evidently similar to typical VLS (max). This plant came from a cross of $C$. maxima cv. "Pink Banana" $\times C$. moschata cv. "Buttercup". The $F_{1}$ plant was backcrossed to the staminate parent, C. moschata cv. "Buttercup". The VLS (max) plant appeared in the backcross progeny. This plant produced a few badly deformed pistillate flowers, but no staminate ones. It died when the runners were about two feet long. The occurrence of this plant suggests that occasionally three species are not required for development of VLS $(\max )$.

We have synthesised many combinations of three or more species of Cucurbita, but unless such hybrids meet the rigid requirements enumerated above, plants with VLS (max) do not appear. Likewise, we have studied several multiple combinations including $C$. maxima that did not produce plants with the virus-like syndrome. If larger populations of these combinations were grown, VLS (max) plants might be detected. The maximum size of our seedling populations from any one progeny is twenty-four plants, but usually only eight plants or less are grown to maturity. The majority of multiple combinations with $C$. maxima, however, do produce individuals with the virus-like syndrome.

\section{(iv) Occurrence of plants with VLS (mos)}

VLS (mos) plants usually occur in the $\mathrm{F}_{1}$ generation where $C$. moschata is used as one parent. The expression does not appear consistently in all interspecific crosses where C. moschata is used or even in crosses where identical species are used as parents.

The expression of VLS (mos) is frequently delayed and becomes visible on what appeared initially to be a normal plant. Likewise, the syndrome is not always stable. There is a dilution effect, i.e., a gradual reversion to normal in some plants. In a few plants the change or reversion is sharply defined and similar in appearance to a somatic mutation.

\section{DISCUSSION}

McNaughton and Harper (1960) reported a virus-like syndrome that appeared in hybrids between Papaver rhoeas L., a diploid $(2 n=14)$, and $P$. dubium L., a hexaploid $(2 n=42)$. The virus-like syndrome in poppies appears to be similar to but not genetically identical with the syndrome in Cucurbita. In poppies, the hybrid individuals exhibiting the virus-like syndrome involve two species with different levels of ploidy, whereas in Cucurbita the species are diploid $(2 n=40)$ and usually a combination of three species, one of which must be C. maxima, are needed for expression of the trait.

Several investigators have reported hereditary characters resembling virus diseases in beans, clover and cucumbers (Burkholder and Muller, I926; Zaumeyer, I938; Atwood and Kreitlow, I946; John and Wilson, 1952). Recently Edwardson and Corbett (r962) discovered a 
Plate I

Fig. 1.-Leaves and tendrils of a plant with VLS (max).

FIG. 2.-VLS (max) dwarf plant showing short, compressed internodes and malformed leaves.

Frg. 3.-VLS (max) plant showing cupping and rolling of the leaves. 

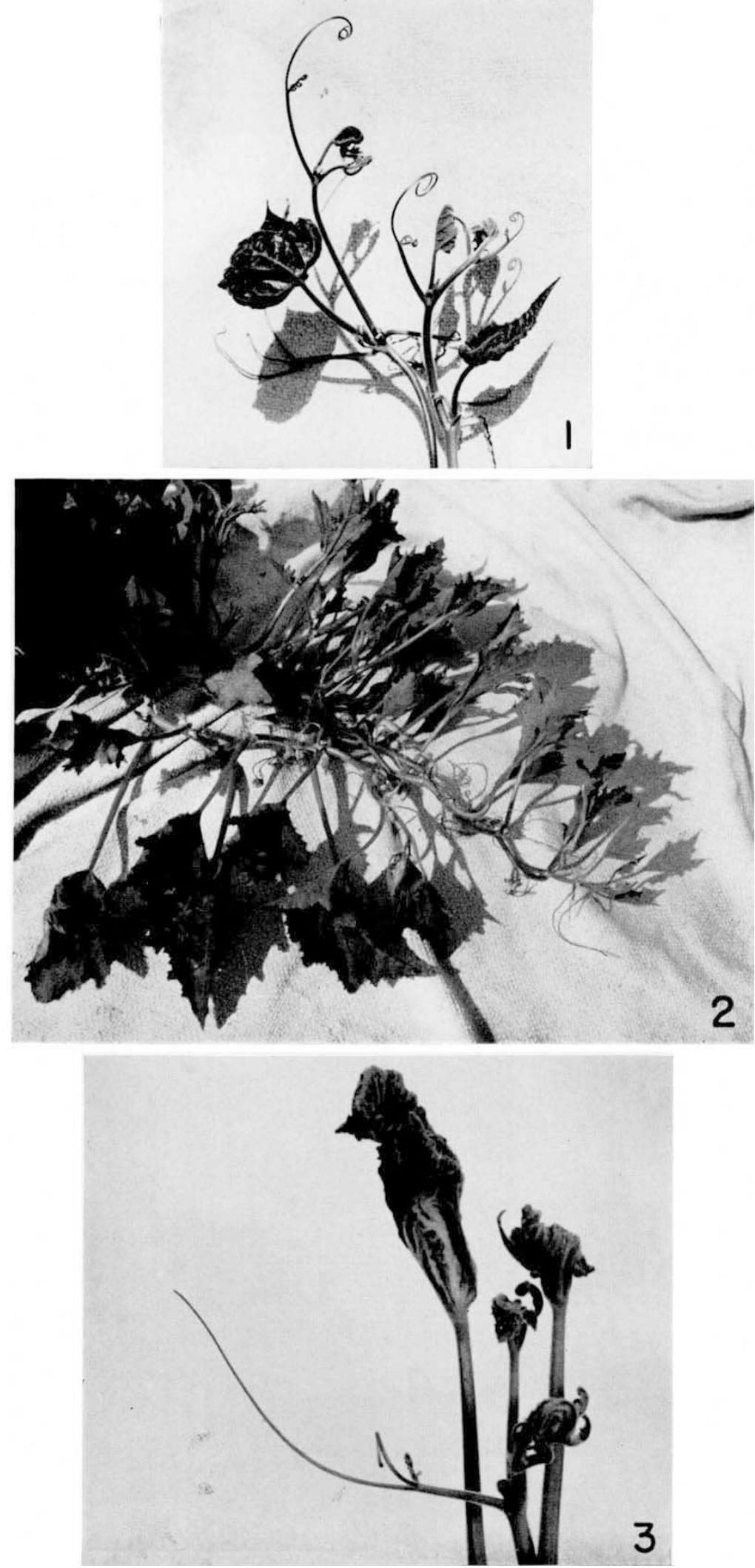


\section{Plate II}

Fig. 1.-A typical VLS (mos) leaf (left) with a normal leaf (right) from different runners of the same plant. The VLS (mos) leaf is much smaller, but of about the same shape as the normal leaf. The grid is marked in one inch squares.

FIG. 2.-A pistillate flower from VLS (max) plant. The corolla is absent and the calyx has become petaliferous.

FIG. 3.-A fruit from a VLS (mos) runner (left), and a fruit from a normal runner of the same plant (right). Note the small size and pebbled appearance of the VLS (mos) fruit. 

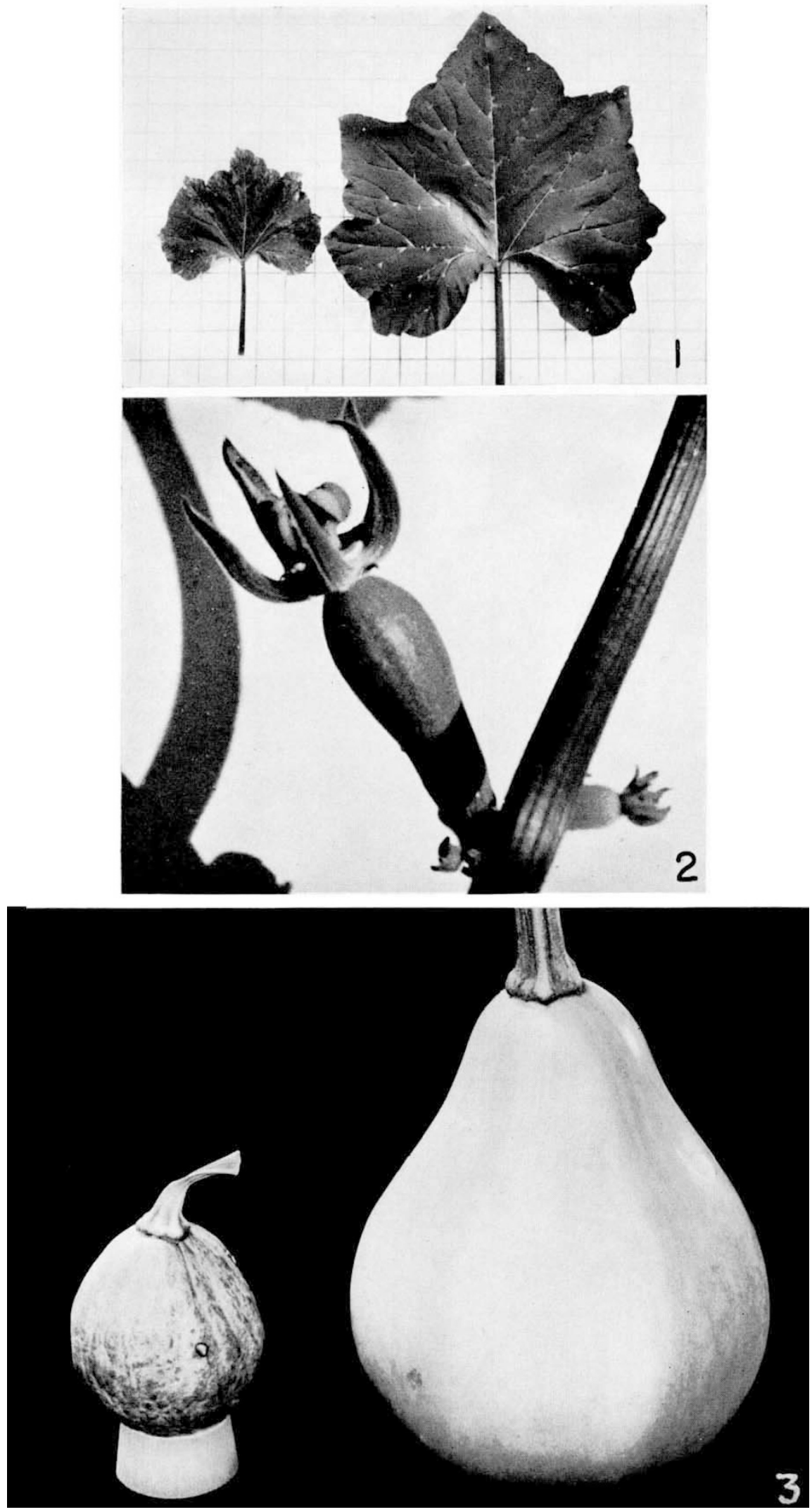
virus-like syndrome in tomato caused by mutation. Phenotypes of the mutant are similar to tomato plants infected with strains of cucumber mosaic virus or tobacco mosaic virus. These investigators show that the mutant phenotype is controlled by a single pair of recessive genes with pronounced pleiotropic effects. In each of the investigations mentioned, the virus-like syndrome was determined not to be caused by a transmissible virus.

It has been suggested that the virus-like syndrome in squash might be interpreted as an example of cytoplasmic inheritance. The evidence, mostly circumstantial, does not support this interpretation. If we grant that the genomes of Cucurbita maxima and C. moschata are required for the production of the disorders, it makes no difference whether the species is introduced into the combination via the pistillate or staminate parent. In other words, the results of reciprocal hybridization are identical.

The sterility of plants with the virus-like syndrome has hampered attempts to obtain a precise reading of its heritable nature. If an occasional fertile pistillate flower could be pollinated with a staminate flower of known parentage some significant data might be obtained. Also, there is the possibility of obtaining self-pollinated fruit from a normal runner on a plant which otherwise exhibits the virus-like syndrome.

Cucurbita species have 20 pairs of chromosomes. The cytology of the triple species hybrids was not investigated, and it is possible that a morphological abnormality among the units of the chromosomes set might be responsible for the occurrence of VLS plants.

The evidence on hand is strongly indicative of a fundamental disharmony between the genomes of Cucurbita maxima and C. moschata and the other species of Cucurbita used in these crosses. Obviously, we have no means of determining whether the disharmony contributed by these two species is confined to a certain group of chromosomes, a single chromosome, or a specific section of a single chromosome. Furthermore, we have assumed that the disharmony is common to all cultivars of $C$. maxima and $C$. moschata, but this assumption may not be valid because only one cultivar of each species was used in the experimental work. For C. maxima, however, several strains of "Banana" from different sources were used with identical results.

\section{SUMMARY}

In a study of species relationships in Cucurbita, several morphological abnormalities were uncovered. The most striking were designated "virus-like syndromes" because they simulate in considerable detail changes in plants caused by infection of cucurbit viruses. Virus-like syndrome plants were separated into two distinct categories on the basis of morphological expressions. They are (1) VLS ( $\max$ ) invariably associated with the Cucurbita maxima genome and (2) VLS (mos) apparently associated with the $C$. moschata genome. 
VLS ( $\max$ ) is usually expressed in progenies from triple species hybrids where one member of the combination is Cucurbita maxima. VLS (mos) is expressed in $\mathrm{F}_{1}$ progenies of certain species hybrids where $C$. moschata is one parent. Also, a VLS (mos) plant appeared in a progeny of a triple species hybrid where C. moschata was a participating species.

The VLS disorders are apparently the result of genetic disharmony caused by the introduction of the genomes of Cucurbita maxima and C. moschata into combinations with other Cucurbita species. Circumstantial evidence indicates the virus-like syndrome disorders are not caused by a transmissible infective agent such as a virus.

Acknowledgment.-The senior author is indebted to Dr R.E. Webb, G.R.D., A.R.S., U.S. Department of Agriculture, for testing virus-like syndrome plants for the presence of cucurbit viruses. Grady A. Sanderson, Agricultural Research Technician, is responsible for the photographs.

\section{REFERENCES}

ATWOOD, s. s., AND KREITLOW, K. W. 1946. Studies of a genetic disease of Trifolium repens simulating a virosis. Amer. Jour. Bot., 33, 91-100.

BURKHOLDER, W. H., AND MULLER, A. s. 1926. Hereditary abnormalities resembling certain infectious diseases in beans. Phytopath., $16,73 \mathrm{I}-737$.

EDWARDSON, J. R., AND CORBETT, M. K. I962. A virus-like syndrome in the tomato caused by a mutation. Amer. Jour. Bot., 49, 57 1-575.

JoHN, C. A., AND WILSON, J. D. 1952. A "Gingko leafed" mutation in the cucumber. Four. Hered., 43, 47-48.

MCNAUGHTON, I. H., AND HARPER, J. L. I I 60 o. The comparative biology of closely related species living in the same area. II. Aberrant morphology and a viruslike syndrome in hybrids between Papaver rhæas L. and $P$. dubium L. New Phytologist, 59, 27-4I.

ZAUMEYER, W. J. I938. A heritable abnormality of beans resembling mosaic. Phytopath., 28, 520-522. 